\title{
Regulations of gene expression in medullary thymic epithelial cells required for preventing the onset of autoimmune diseases
}

\author{
Taishin Akiyama $^{1}$, Miho Shinzawa ${ }^{1}$, Junwen Qin ${ }^{1,2}$ and Nobuko Akiyama1 \\ ${ }^{1}$ Division of Cellular and Molecular Biology, Institute of Medical Science, University of Tokyo, Tokyo, Japan \\ ${ }^{2}$ Key Laboratory for Regenerative Medicine, Department of Developmental and Regenerative Biology, Ministry of Education and International Base of Collaboration \\ for Science and Technology, the Ministry of Science and Technology and Guangdong Province, Jinan University, Guangzhou, China
}

\section{Edited by:}

Claudio Pignata, Federico II

University, Italy

Reviewed by:

Anna Villa, National Council of

Research, Italy

Petteri Arstila, University of Helsinki,

Finland

\section{*Correspondence}

Taishin Akiyama, Division of Cellular and Molecular Biology, Institute of

Medical Science, University of Tokyo,

4-6-1 Shirokane-dai, Minato-ku, Tokyo 108-8639, Japan

e-mail: taishin@ims.u-tokyo.ac.jp
Elimination of potential self-reactive T cells in the thymus is crucial for preventing the onset of autoimmune diseases. Epithelial cell subsets localized in thymic medulla [medullary thymic epithelial cells (mTECs)] contribute to this process by supplying a wide range of self-antigens that are otherwise expressed in a tissue-specific manner (TSAs). Expression of some TSAs in mTECs is controlled by the autoimmune regulator (AIRE) protein, of which dysfunctional mutations are the causative factor of autoimmune polyendocrinopathycandidiasis-ectodermal dystrophy (APECED). In addition to the elimination of self-reactive $T$ cells, recent studies indicated roles of MTECs in the development of Foxp3-positive regulatory $T$ cells, which suppress autoimmunity and excess immune reactions in peripheral tissues. The TNF family cytokines, RANK ligand, CD40 ligand, and lymphotoxin were found to promote the differentiation of AIRE- andTSA-expressing mTECs. Furthermore, activation of NF-KB is essential for mTEC differentiation. In this mini-review, we focus on molecular mechanisms that regulate induction of AIRE and TSA expression and discuss possible contributions of these mechanisms to prevent the onset of autoimmune diseases.

Keywords: medullary thymic epithelial cells, autoimmune disease, NF- $\mathrm{kB}$, TNF receptor family, gene expression

\section{INTRODUCTION}

The thymus contributes to self-tolerance of $\mathrm{T}$ cells by eliminating potentially self-reactive $T$ cells and generating immunosuppressive $\mathrm{T}$ cells, which are essential for preventing the onset of autoimmune disease. Epithelial cells localized in the thymic medulla [medullary thymic epithelial cells (mTECs)] are non-hematopoietic in origin and play non-redundant roles in the elimination of self-reactive $\mathrm{T}$ cells (1-4). Recent studies have revealed that mTECs also contribute to the selection and survival of immunosuppressive Foxp3-positive regulatory T cells (Tregs) (5-8).

Medullary thymic epithelial cells express several functional molecules required for the selection of self-tolerant $\mathrm{T}$ cells and Tregs (3). Mature types of mTECs express MHC molecules and co-stimulatory molecules essential for antigen presentation to developing $\mathrm{T}$ cells. In addition, mTECs secrete several types of chemokines (e.g., CCL19, CCL21, and CCL22) that attract T cells or dendritic cells in the medulla $(2,9)$. Moreover, a recent study has shown that the expression of CD70 in mTECs enhances the development and survival of Tregs via an interaction with its receptor, $\mathrm{CD} 27$, which is expressed on thymic T cells (5). A key feature of mTECs is their ability to express hundreds of self-antigens that are normally expressed in a tissue-specific manner (TSAs) $(4,10)$. TSAs are processed and directly presented by mTECs or indirectly presented by thymic DCs receiving TSAs from mTECs $(4,7,11-13)$. T cells that recognize TSAs with high avidity undergo apoptosis (so-called negative selection) or survive as regulatory $\mathrm{T}$ cells $(4,14)$. Many studies have suggested significant roles of mTEC-dependent self-tolerance in preventing the onset of some autoimmune diseases in humans. Expression of some TSAs requires a nuclear protein autoimmune regulator (AIRE), the dysfunctional mutations of which are responsible for an inherited human autoimmune disease, autoimmune polyendocrinopathycandidiasis-ectodermal dystrophy (APECED) $(15,16)$. Whereas the expression of AIRE mRNA is detected in different cell types, AIRE expression at the protein level is remarkably high in mTECs (17). A previous study using AIRE-deficient mice provided evidence that autoimmunity, provoked by dysfunction of AIRE, is thymic stroma-dependent (18). In addition to APECED, recent studies have demonstrated that single-nucleotide polymorphisms (SNPs) in the AIRE gene are associated with rheumatoid arthritis $(19,20)$. In addition to mutations in the AIRE gene, reduced expression of the muscle acetyl choline receptor (CHRNA1) in mTECs was shown to be associated with the onset of myasthenia gravis (21). Moreover, impairment of the mTEC-dependent tolerance might explain the relationship between myocarditis and autoimmunity (22). These findings also imply that the onsets of various human autoimmune diseases could be related to dysregulation of mTEC-dependent tolerance. Interestingly, in addition to relationships with autoimmune diseases, recent studies have uncovered roles for mTEC-dependent T-cell tolerance in tumor tolerance $(8,23,24)$.

Because expression of AIRE and TSAs is characteristic of mTEC, mTECs should harbor specific mechanisms to direct AIRE and TSA expression. Expression of TSAs appears to be correlated 
with the differentiation of mTECs. In this mini-review, we specially focus on molecular mechanisms regulating the expression of AIRE and TSAs and the process of mTEC differentiation.

\section{DEVELOPMENT OF mTECs}

Thymic epithelial cells are classified into mTECs and cortical thymic epithelial cells (cTECs) (2). Several lines of evidence indicate the existence of a bi-potent TEC progenitor capable of differentiating into mTECs and cTECs in the fetal and adult thymus (25-29). The bi-potent TEC progenitor seems to give rise to each progenitor of mTECs and cTECs in the next stage (30, 31). Recent studies revealed that mTECs differentiate from progenitors expressing cTEC-markers $(32,33)$. These data imply that mechanisms determining the mTEC commitment suppress the cTEC-driving program. However, master molecules that decide the fate of the bi-potent TEC progenitor expressing cTEC-markers to the mTEC lineage have not been determined yet.

Currently, mTECs are classified based on the expression of MHC II, CD80, AIRE, and involucrin (Figure 1). mTECs (typically defined as $\mathrm{CD}_{4}{ }^{-} \mathrm{EpCAM}^{+} \mathrm{Ly}_{51}{ }^{-}$and UEA- ${ }^{+}$by flow cytometric analysis) in adult mice are divided into two subpopulations, according to the expression levels of MHC II and CD80 (34). mTECs expressing high levels of MHC II and CD80 $\left(\mathrm{mTEC}^{\text {hi }}\right)$ express a more diverse set of TSAs than mTECs expressing lower levels of MHC II and CD80 (mTEC ${ }^{\text {lo }}$ ) do (35). Moreover, precursor-product relationship analysis has suggested that the mTEC $^{\text {lo }}$ fraction can differentiate into $\operatorname{mTEC}^{\text {hi }}(36,37)$. Therefore, the $\mathrm{mTEC}^{\text {hi }}$ fraction would be the more mature type of mTEC than mTEC $^{\text {lo }}$.

The mTEC $^{\text {hi }}$ fraction is further separated on the basis of AIRE expression $(36,38)$. Because previous studies have indicated that the AIRE-expressing mTECs ${ }^{\text {hi }}\left(\mathrm{AIRE}^{+} \mathrm{mTEC}^{\text {hi }}\right.$ ) are postmitotic and susceptible to apoptosis (36), AIRE $^{+}$mTECs $^{\text {hi }}$ are postulated to be the more differentiated cell types than AIRE-negative mTECs ${ }^{\text {hi }}$. mTECs expressing involucrin, a marker of terminally differentiated keratinocytes, are considered to be terminally differentiated mTECs that may be derived from $\operatorname{AIRE}^{+}$mTEC $^{\text {hi }}(39,40)$.

\section{REGULATION OF AIRE mRNA EXPRESSION}

Molecular mechanisms regulating the expression of AIRE, which are likely critical for preventing autoimmunity, remain unclear. In the fetal thymus, expression of AIRE starts at embryonic day 14.5 (41). Consistently, mature mTECs emerge around this embryonic day (42). Thus, AIRE expression seems to be closely linked to mTEC differentiation. However, because mTEC $^{\text {hi }}$ is separated into $\mathrm{AIRE}^{+}$and $\mathrm{AIRE}^{-}$fractions, the mTEC differentiation mechanism might be necessary but is not entirely sufficient for AIRE expression.

A study using a luciferase reporter assay identified a plausible minimal promoter region of the AIRE gene (43). This region contains binding sequences for Sp1, AP-1, NF-Y, and ETS family of transcription factors. Indeed, luciferase reporter analysis suggested regulation of the AIRE gene promoter by ETS family proteins (44). However, in vivo genetic studies are necessary to prove that these sequence-specific transcription factors are critical for the regulation of AIRE expression.

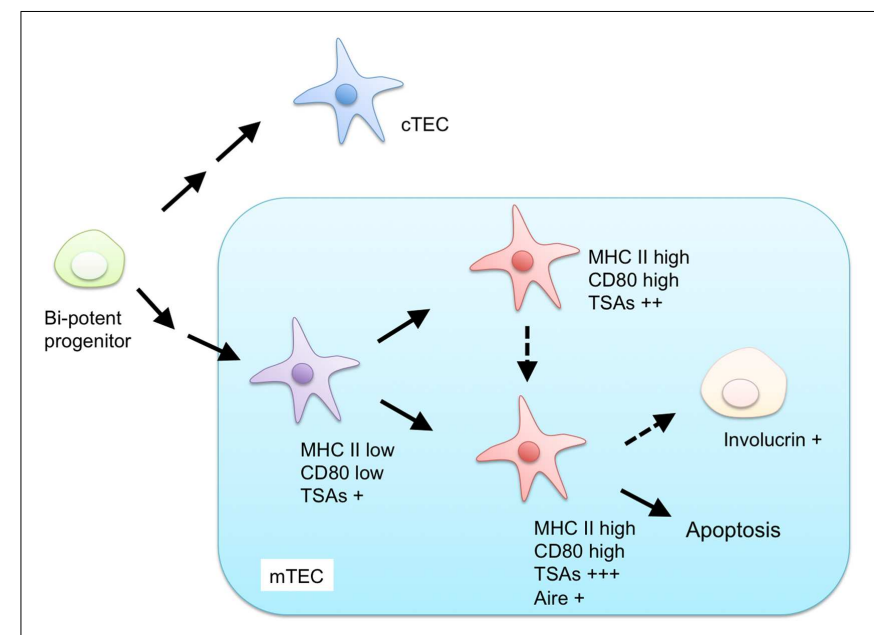

FIGURE 1 | Proposed model for differentiation of $\mathbf{m T E C s}$. Both mTECs and CTECs are generated from a bi-potent progenitor in the fetal and adult thymus. mTECs are classified by expression of MHC class II (MHC II), CD80, AIRE, and involucrin. mTECs expressing low levels of MHC II and $\mathrm{CD} 80$ are considered immature and give rise to mature mTECs, expressing high levels of MHC II and CD80, and a more diverse set of tissue-specific antigens (TSAs). MHC II-high and CD80-high mature mTECs are further separated into AIRE-positive and AIRE-negative subpopulations.

AIRE-positive mature mTECs are postmitotic and undergo apoptosis or otherwise differentiate into involucrin-positive mTECs.

The promoter region of AIRE contains a high ratio of CpG sites (43). These CpG sites are hypermethylated in established cell lines defective in the AIRE expression. A subsequent study showed that these $\mathrm{CpG}$ sites are hypomethylated in isolated mTECs compared to thymocytes (45). These findings suggest that DNA demethylation might be prerequisite for AIRE expression. However, interestingly, hypomethylation was also observed in cTECs and thymoma with defective AIRE expression (45). Hence, DNA hypomethylation appears to be required but not sufficient for inducing AIRE expression.

Overall, AIRE expression seems to be regulated by combinations of chromatin modification and sequence-specific transcription factors. However, precise mechanisms and regulatory molecules remain to be determined.

\section{REGULATION OF TSA mRNA EXPRESSION}

TSA expression appears to be regulated by complicated mechanisms. Single-cell PCR analyses revealed a stochastic nature of TSA expression in mTECs $(38,46)$. Each TSA is expressed in a subset of mTECs $(38,46)$. The frequency of mTECs expressing a particular TSA was different, depending on the TSA $(38,46)$. Interestingly, various combinations of TSAs are expressed in individual mTECs $(38,46)$. These studies suggest that regulatory mechanisms of TSA expression in mTECs are different from those used in inherent tissues.

Several studies suggest that TSA expressions are epigenetically controlled. A comprehensive mRNA expression study revealed that TSA gene loci tend to co-localize in chromosomal clusters $(35,47)$. Moreover, genomic imprinting of the Igf2 gene, a TSA, was lost in mTECs (35), implicating the involvement of 
a DNA demethylation mechanism in TSA expression. Interestingly, another imprinted gene, $C d k n 1 c$, was not affected. These data imply the existence of mTEC-specific mechanisms for demethylation of DNA.

Control of TSA gene expression by AIRE has been intensively studied (48-50). Several studies have revealed a function of AIRE as a transcription factor that directly promotes TSA expression $(51,52)$. Furthermore, AIRE binds to hypomethylated Histone 3 Lys 4 (H3K4) through its plant homology domain $(53,54)$. This finding suggests that AIRE modifies the chromatin structure in the TSA genes. AIRE also binds to DNA-PK (55-57), which functions in the repair of DNA-double strand breakage. A study using an mTEC cell line suggested that interactions of AIRE with H3K4 and DNA-PK are critical in recruiting AIRE to TSA gene loci and promoting TSA expression (57). Additionally, it was reported that AIRE interacts with P-TEFb, a component of the super elongation complex (58). It is generally accepted that transcription elongation, via the release of "paused" RNA polymerase II, is critical for the regulation of many genes $(58,59)$. AIRE may recruit P-TEFb to the TSA gene locus and promote elongation of the arrested TSA transcripts by releasing RNA polymerase II from the proximal promoter (60). Recent comprehensive analysis of mRNA transcripts in mTECs supports this mechanism (61). In addition to the TSA expression, the AIRE-dependent expression of some microRNAs (miRNAs) was recently revealed $(62,63)$. Consistently, genetic studies revealed important roles played by miRNA expressions in functions and maintenance of mTECs (63-65).

Compared to the mechanisms underlying Aire-dependent TSA expression, molecular mechanisms underlying Aire-independent TSA expression are less understood. As described above, whereas epigenetic regulations of TSA genes would be critical, mechanisms underlying epigenetic changes specific for mature mTECs remain unclear. Moreover, unidentified transcription factors may be involved in the promotion of Aire-independent TSA expressions.

\section{EXTRACELLULAR SIGNALING TO PROMOTE DIFFERENTIATION OF mTECs EXPRESSING AIRE AND TSAs}

Differentiation of TECs is well known to be correlated to differentiation of $\mathrm{T}$ cells in the thymus (so-called thymic cross-talk) (3). mTEC maturation was reported to be abolished in severe combined immunodeficiency (SCID) patients (66). This finding supports the idea that failure of the thymic cross-talk results in the onset of autoimmune manifestation through inhibition of mTEC function. Interestingly, a recent study showed that administration of anti-CD3 $\varepsilon$ antibody ameliorated autoimmunity in leaky SCID model mice possibly through improvement of the thymic cross-talk (67).

Molecular basis of the thymic cross-talk in mTEC development has been reported. Several lines of evidence revealed that TNF family cytokines expressed in thymocytes and other cells of hematopoietic origin (2) and their receptors expressed in mTEC are critical for the thymic cross-talk. Briefly, signaling of TNF receptor family members, RANK, CD40, and lymphotoxin- $\beta$ receptor $(\mathrm{Lt} \beta \mathrm{R})$, play essential roles in the development of mTECs expressing Aire and TSAs. This topic has been summarized in a recent review (1).

\section{DOWNSTREAM OF TNF RECEPTOR FAMILY SIGNALING}

TNF receptor family signaling induces the activation of NF- $\kappa \mathrm{B}$ and MAPK pathways (68). To date, the involvement of the MAPK pathway in the development of mTEC remains to be addressed. However, several lines of evidence have indicated that the NF-кB family plays a critical role in the development of mTECs expressing AIRE and TSAs.

NF- $\kappa \mathrm{B}$ members are sequestered in the cytoplasm in an inactive state by the binding of the inhibitory protein $\mathrm{I} \kappa \mathrm{B}$ in resting cells (69-71). Ligations of receptors induce phosphorylation and subsequent degradation of I $\mathrm{KB}$ proteins, thereby leading to nuclear localization of NF- $\kappa \mathrm{B}$ to activate transcription. Two distinct NF$\kappa \mathrm{B}$ activation pathways, the classical pathway and the non-classical pathway, are currently known (70-72) (Figure 2). The classical pathway is required in inflammatory responses and lymphocyte activation (71). On the other hand, the non-classical pathway mainly promotes development and architecture formation of lymphoid organs, including the thymus. In the non-classical pathway, receptor ligation induces accumulation of the NF-кB-inducing kinase (NIK), which is normally degraded by the ubiquitindependent proteasome in resting cells. Subsequently, accumulated NIK phosphorylates and activates IKK $\alpha$, which induces partial degradation of p100 to p52. p100 preferentially binds to and sequesters RelB in the cytoplasm, and the partial degradation of p100 to p52 induces translocation of RelB and p52 as a heterodimer into the nucleus.

The requirement for NF- $\kappa \mathrm{B}$ activation in the development of mTEC was initially identified by the analysis of RelB-deficient mice $(73,74)$. RelB-deficient mice showed severe reduction in medulla size, accompanied by a lack of UEA-1-positive mTECs. Consistently, the expression of AIRE was abolished in the RelBdeficient thymus $(6,41,75)$. As expected, RelB-deficient mice showed severe autoimmune diseases. A recent study demonstrated that autoimmunity of RelB mice was due to the defect in thymic stroma function (6). Mice carrying a dysfunctional mutation, NIK (aly/aly), also showed a similar defect in mTEC development and autoimmune phenotypes (76-78). Whereas IKK $\alpha$-deficient mice die shortly after birth, neonatal IKK $\alpha$-deficient mice and transplantation of IKK $\alpha$-deficient thymic stroma indicates a requirement of IKK $\alpha$ in the development of mTECs $(79,80)$. mTEC development in p100-deficient mice is partially defective $(81,82)$, but this appears to be due to a partial rescue of p100 function by p105 (or its processed product, p50) because the double deficiencies of p100 and p105 resulted in severe defects in mTEC development, similar to the RelB- and NIK-mutant mice (83). Overall, these results support the idea that activation of the non-classical NF- $\mathrm{B}$ pathway is essential for the development of mTECs.

TRAF6 is a signal transducer that mediates signaling from TNF receptor family members $(84,85)$. TRAF6-deficient mice exhibit severe autoimmune disease $(86,87)$. Additionally, recent studies suggest possible associations between SNPs of the TRAF6 gene with rheumatoid arthritis and systemic lupus erythematosus in humans $(88,89)$. Previous studies showed that TRAF6 promotes the development of mTECs expressing AIRE and TSAs, thereby suppressing autoimmunity (86). Moreover, RANK-mediated differentiation of mTECs requires TRAF6 in in vitro organ culture 


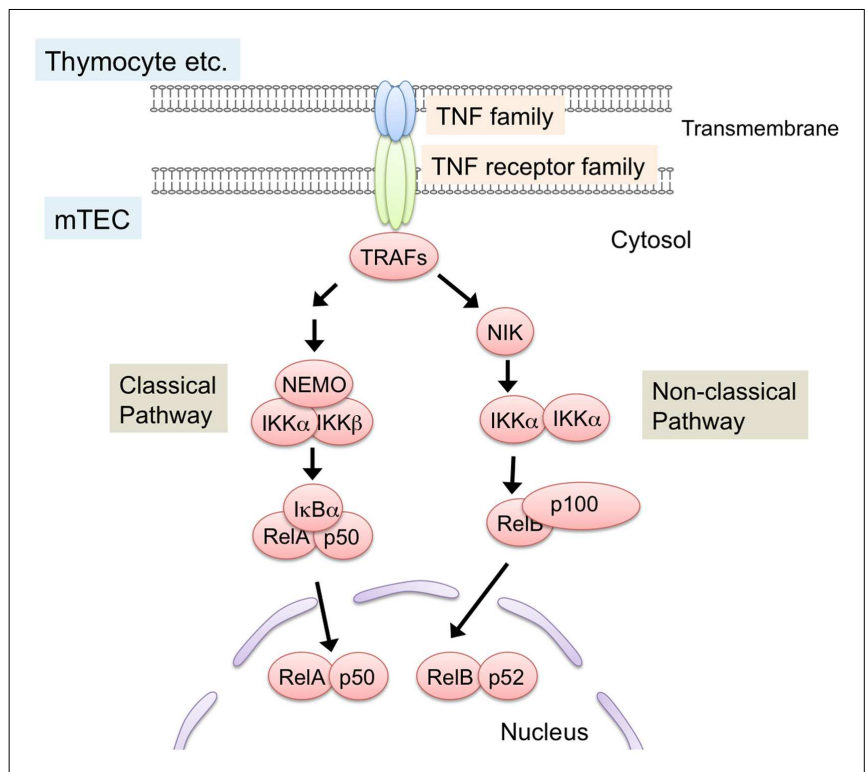

FIGURE 2 | NF- $\kappa$ B activation pathways triggered by TNF family signaling. Interaction of TNF family ligand (RANK ligand, CD40 ligand, and lymphotoxin $\alpha$ and $\beta$ complex) with their respective receptors (RANK, $\mathrm{CD} 40$, and $L t \beta R$ ) induces activation of NF- $\mathrm{B} B$ pathways. Interaction between the ligand and its receptor induce the binding of TRAF-family proteins to the cytoplasmic domains of TNF receptors. TRAF-family proteins in turn activate downstream serine/threonine kinase cascade. These kinases trigger the degradation of inhibitory proteins that sequester NF-kB in cytosol, thereby leading to the translocation and transcriptional activation of NF- $\mathrm{B}$ members. NF-kB pathways are classified into classical and non-classical pathway. In the non-classical pathway, NF-kB complex consisting of RelB and p52 is activated. NIK is critical for the non-classical NF-kB pathway. TRAF6, a member of the TRAF protein family, was reported to regulate only the classical NF-kB pathway, which causes nuclear translocation of mainly the RelA complex. On the other hand, other TRAF members function in the non-classical NF-kB pathway by binding to the TNF family receptors.

of fetal thymic stroma (90). Notably, TRAF6 is a signal transducer that mediates the activation of the classical NF- $\kappa \mathrm{B}$ pathway but not the non-classical NF- $\kappa$ B pathway $(84,85)$. Thus, these data imply a role for TRAF6-mediated activation of the classical NF- $\kappa$ B pathway in mTEC differentiation.

\section{REFERENCES}

1. Akiyama T, Shinzawa M, Akiyama N. TNF receptor family signaling in the development and functions of medullary thymic epithelial cells. Front Immunol (2012) 3: 278. doi:10.3389/fimmu.2012. 00278

2. Anderson G, Takahama Y. Thymic epithelial cells: working class heroes for $\mathrm{T}$ cell development and repertoire selection. Trends Immunol (2012) 33:256-63. doi:10.1016/j.it. 2012.03.005

3. Gill J, Malin M, Sutherland J, Gray D, Hollander G, Boyd R. Thymic generation and regeneration. Immunol Rev (2003) 195: 28-50. doi:10.1034/j.1600-065X. 2003.00077.x
4. Kyewski B, Klein L. A central role for central tolerance. Annu Rev Immunol (2006) 24:571-606. doi:10.1146/annurev.immunol.23. 021704.115601

5. Coquet JM, Ribot JC, Babala N, Middendorp S, van der Horst G, Xiao Y, et al. Epithelial and dendritic cells in the thymic medulla promote CD4+Foxp3+ regulatory $\mathrm{T}$ cell development via the CD27-CD70 pathway. J Exp Med (2013) 210:715-28. doi:10.

6. Cowan JE, Parnell SM, Nakamura $\mathrm{K}$, Caamano JH, Lane PJ, Jenkinson EJ, et al. The thymic medulla is required for Foxp3+ regulatory but not conventional CD4+ thymocyte development. J Exp Med (2013) 1084/jem.20112061

In addition to the above findings, a scaffold protein, Sin (also called Efs), was proposed to be expressed downstream of TNF receptor family signaling. Sin-deficient mice showed reduced numbers of mTECs and thymic stroma-dependent autoimmunity (91). In addition to the role of Sin in FGF-mediated proliferation signaling (91), a recent study suggested that Sin might regulate the non-classical NF- $\mathrm{B}$ pathway activated by RANKL signaling (92). Because the $\mathrm{SH} 3$ domain and phosphorylation of tyrosine residues of Sin might be critical for its function $(93,94)$, these studies also imply unrecognized roles of Src-type tyrosine kinases in mTEC development.

\section{CONCLUDING REMARIS}

Whereas significant roles for NF- $\kappa \mathrm{B}$ in signal activation of mTEC differentiation and subsequent expression of AIRE and TSAs are indisputable, molecular events connecting these signaling pathways to induction of AIRE and TSA remain unclear. It was reported that Lt $\beta R$ signaling induces the expression of AIRE in an mTEC line in the presence of a DNA methylation inhibitor (95). However, it is still unclear whether NF- $\mathrm{B}$ binds to the promoter of the AIRE gene. Moreover, a wide variety of TSA expression would not be explained only by NF- $\kappa \mathrm{B}$-dependent transcriptional activation because NF- $\kappa$ B family members are generally known to be sequence-specific transcription factors. Thus, the link between NF- $\kappa$ B activation and expression of AIRE and TSAs remains largely enigmatic.

In addition, differentiation stages regulated by these signaling molecules and their mechanisms need to be clarified. mTECs have different properties in each developmental stage, with regard to TSA expression, AIRE expression, and DNA methylation status. Therefore, it is important to clarify types of mTECs in which each TNF receptor family signal functions. Overall, more studies are needed to understand the molecular and cellular mechanisms regulating the development of mTECs with the final aim to develop novel therapeutic strategies preventing autoimmune diseases caused by defective thymic functions.

\section{ACKNOWLEDGMENTS}

This work was supported by a grant from the Japanese Society for the Promotion of Science (Taishin Akiyama).

210:675-81. doi:10.1084/jem. 20122070

7. Hinterberger $M$, Aichinger $M$, da Costa O, Voehringer D, Hoffmann R, Klein L. Autonomous role of medullary thymic epithelial cells in central CD4(+) $\mathrm{T}$ cell tolerance. Nat Immunol (2010) 11:512-9. doi:10.1038/ni. 1874

8. Malchow S, Leventhal DS, Nishi S, Fischer BI, Shen L, Paner GP, et al. Aire-dependent thymic development of tumor-associated regulatory T cells. Science (2013) 339:1219-24. doi:10.1126/science. 1233913

9. Takahama Y. Journey through the thymus: stromal guides for T-cell development and selection. Nat Rev
Immunol (2006) 6:127-35. doi:10. 1038/nri1781

10. Derbinski J, Schulte A, Kyewski B, Klein L. Promiscuous gene expression in medullary thymic epithelial cells mirrors the peripheral self. Nat Immunol (2001) 2:1032-9. doi:10.1038/ni723

11. Derbinski J, Kyewski B. How thymic antigen presenting cells sample the body's self-antigens. Curr Opin Immunol (2010) 22:592-600. doi: 10.1016/j.coi.2010.08.003

12. Guerder S, Viret C, Luche $H$, Ardouin L, Malissen B. Differential processing of self-antigens by subsets of thymic stromal cells. Curr Opin Immunol (2012) 24: 99-104. doi:10.1016/j.coi.2012.01. 008 
13. Klein L, Hinterberger M, Wirnsberger G, Kyewski B. Antigen presentation in the thymus for positive selection and central tolerance induction. Nat Rev Immunol (2009) 9:833-44. doi:10.1038/nri2669

14. Xing Y, Hogquist KA. T-cell tolerance: central and peripheral. Cold Spring Harb Perspect Biol (2012) 4. doi:10.1101/cshperspect.a006957

15. Consortium F-GA. An autoimmune disease, APECED, caused by mutations in a novel gene featuring two PHD-type zinc-finger domains. Nat Genet (1997) 17:399-403. doi:10. 1038/ng1297-399

16. Nagamine K, Peterson P, Scott H, Kudoh J, Minoshima S, Heino M, et al. Positional cloning of the APECED gene. Nat Genet (1997) 17:393-8. doi:10.1038/ng1297-393

17. Hubert FX, Kinkel SA, Webster KE, Cannon P, Crewther PE, Proeitto $\mathrm{AI}$, et al. A specific anti-Aire antibody reveals Aire expression is restricted to medullary thymic epithelial cells and not expressed in periphery. J Immunol (2008) 180: 3824-32.

18. Anderson M, Venanzi E, Klein L, Chen Z, Berzins S, Turley S, et al. Projection of an immunological self shadow within the thymus by the Aire protein. Science (2002) 298:1395-401. doi:10.1126/science. 1075958

19. García-Lozano JR, Torres-Agrela B, Montes-Cano MA, OrtizFernández L, Conde-Jaldón $\mathrm{M}$, Teruel M, et al. Association of the AIRE gene with susceptibility to rheumatoid arthritis in a European population: a case control study. Arthritis Res Ther (2013) 15:R11. doi:10.1186/ar4141

20. Terao C, Yamada R, Ohmura K, Takahashi M, Kawaguchi T, Kochi $\mathrm{Y}$, et al. The human AIRE gene at chromosome $21 \mathrm{q} 22$ is a genetic determinant for the predisposition to rheumatoid arthritis in Japanese population. Hum $\mathrm{Mol}$ Genet (2011) 20:2680-5. doi:10. 1093/hmg/ddr161

21. Giraud M, Taubert R, Vandiedonck C, Ke X, Lévi-Strauss M, Pagani F, et al. An IRF8-binding promoter variant and AIRE control CHRNAl promiscuous expression in thymus. Nature (2007) 448:934-7. doi:10. 1038/nature06066

22. Lv H, Havari E, Pinto S, Gottumukkala RV, Cornivelli L, Raddassi K, et al. Impaired thymic tolerance to $\alpha$-myosin directs autoimmunity to the heart in mice and humans. J Clin Invest (2011) 121:1561-73. doi:10.1172/JCI44583
23. Träger U, Sierro S, Djordjevic G, Bouzo B, Khandwala S, Meloni A, et al. The immune response to melanoma is limited by thymic selection of self-antigens. PLoS ONE (2012) 7:e35005. doi:10.1371/ journal.pone.0035005

24. Zhu ML, Nagavalli A, Su MA. Aire deficiency promotes TRP-1-specific immune rejection of melanoma. Cancer Res (2013) 73:2104-16. doi: 10.1158/0008-5472.CAN-12-3781

25. Bennett AR, Farley A, Blair NF Gordon J, Sharp L, Blackburn CC. Identification and characterization of thymic epithelial progenitor cells. Immunity (2002) 16: 803-14. doi:10.1016/S10747613(02)00321-7

26. Bleul CC, Corbeaux T, Reuter A, Fisch P, Mönting JS, Boehm T. Formation of a functional thymus initiated by a postnatal epithelial progenitor cell. Nature (2006) 441:9926. doi:10.1038/nature 04850

27. Gill J, Malin M, Holländer GA, Boyd R. Generation of a complete thymic microenvironment by MTS24(+) thymic epithelial cells. Nat Immunol (2002) 3:635-42. doi:10.1038/ni812

28. Rossi SW, Jenkinson WE, Anderson G, Jenkinson EJ. Clonal analysis reveals a common progenitor for thymic cortical and medullary epithelium. Nature (2006) 441:98891. doi:10.1038/nature04813

29. Senoo M, Pinto F, Crum CP, McKeon F. p63 Is essential for the proliferative potential of stem cells in stratified epithelia. Cell (2007) 129:523-36. doi:10.1016/j. cell.2007.02.045

30. Hamazaki Y, Fujita H, Kobayashi T, Choi Y, Scott HS, Matsumoto M, et al. Medullary thymic epithelial cells expressing Aire represent a unique lineage derived from cells expressing claudin. Nat Immunol (2007) 8:304-11. doi:10.1038/nil438

31. Rodewald HR, Paul S, Haller C, Bluethmann H, Blum C. Thymus medulla consisting of epithelial islets each derived from a single progenitor. Nature (2001) 414:7638. doi:10.1038/414763a

32. Baik S, Jenkinson EJ, Lane PJ, Anderson G, Jenkinson WE. Generation of both cortical and Aire (+) medullary thymic epithelial compartments from CD205(+) progenitors. Eur J Immunol (2013) 43:589-94. doi:10. 1002/eji.201243209

33. Ohigashi I, Zuklys S, Sakata M, Mayer CE, Zhanybekova S, Murata $S$, et al. Aire-expressing thymic medullary epithelial cells originate from $\beta 5$ t-expressing progenitor cells. Proc Natl Acad Sci U S
A (2013) 110:9885-90. doi:10.1073/ pnas. 1301799110

34. Gray DH, Seach N, Ueno T, Milton MK, Liston A, Lew AM, et al. Developmental kinetics, turnover and stimulatory capacity of thymic epithelial cells. Blood (2006) 108:3777-85. doi:10.1182/blood2006-02-004531

35. Derbinski J, Gäbler J, Brors B, Tierling S, Jonnakuty S, Hergenhahn M, et al. Promiscuous gene expression in thymic epithelial cells is regulated at multiple levels. J Exp Med (2005) 202:33-45. doi:10.1084/jem. 20050471

36. Gray D, Abramson J, Benoist C, Mathis D. Proliferative arrest and rapid turnover of thymic epithelial cells expressing Aire. J Exp Med (2007) 204:2521-8. doi:10. 1084/jem.20070795

37. Gäbler J, Arnold J, Kyewski B. Promiscuous gene expression and the developmental dynamics of medullary thymic epithelial cells. Eur J Immunol (2007) 37:3363-72. doi:10.1002/eji.200737131

38. Villaseñor J, Besse W, Benoist C, Mathis D. Ectopic expression of peripheral-tissue antigens in the thymic epithelium: probabilistic, monoallelic, misinitiated. Proc Nat Acad Sci U S A (2008) 105:15854-9. doi:10.1073/pnas.0808069105

39. Hale LP, Markert ML. Corticosteroids regulate epithelial cell differentiation and Hassall body formation in the human thymus. $J$ Immunol (2004) 172:617-24.

40. Yano M, Kuroda N, Han H, MeguroHorike M, Nishikawa Y, Kiyonari H, et al. Aire controls the differentiation program of thymic epithelial cells in the medulla for the establishment of self-tolerance. $J$ Exp Med (2008) 205:2827-38. doi:10.1084/ jem.20080046

41. Zuklys S, Balciunaite G, Agarwal A, Fasler-Kan E, Palmer E, Holländer GA. Normal thymic architecture and negative selection are associated with Aire expression, the gene defective in the autoimmune-polyendocrinopathycandidiasis-ectodermal dystrophy (APECED). J Immunol (2000) 165:1976-83.

42. Surh CD, Gao EK, Kosaka H, Lo D, Ahn C, Murphy DB, et al. Two subsets of epithelial cells in the thymic medulla. JExp Med (1992) 176:495505. doi:10.1084/jem.176.2.495

43. Murumägi A, Vähämurto P, Peterson $\mathrm{P}$. Characterization of regulatory elements and methylation pattern of the autoimmune regulator (AIRE) promoter. J Biol Chem
(2003) 278:19784-90. doi:10.1074/ jbc.M210437200

44. Murumägi A, Silvennoinen O, Peterson P. Ets transcription factors regulate AIRE gene promoter. Biochem Biophys Res Commun (2006) 348:768-74. doi:10. 1016/j.bbrc.2006.07.135

45. Kont V, Murumägi A, Tykocinski LO, Kinkel SA, Webster KE, Kisand $\mathrm{K}$, et al. DNA methylation signatures of the AIRE promoter in thymic epithelial cells, thymomas and normal tissues. Mol Immunol (2011) 49:518-26. doi:10. 1016/j.molimm.2011.09.022

46. Derbinski J, Pinto S, Rösch S, Hexel K, Kyewski B. Promiscuous gene expression patterns in single medullary thymic epithelial cells argue for a stochastic mechanism. Proc Natl Acad Sci U S A (2008) 105:657-62. doi:10.1073/ pnas.0707486105

47. Johnnidis JB, Venanzi ES, Taxman DJ, Ting JP, Benoist CO, Mathis DJ. Chromosomal clustering of genes controlled by the aire transcription factor. Proc Natl Acad Sci U S A (2005) 102:7233-8. doi:10.1073/ pnas.0502670102

48. Mathis D, Benoist C. Aire. Annu Rev Immunol (2009) 27:287-312. doi:10.1146/annurev.immunol.25. 022106.141532

49. Wu G, Hirabayashi K, Sato S, Akiyama N, Akiyama T, Shiota K, et al. DNA methylation profile of Airedeficient mouse medullary thymic epithelial cells. BMC Immunol (2012) 13:58. doi:10.1186/14712172-13-58

50. Zumer K, Saksela K, Peterlin BM. The mechanism of tissue-restricted antigen gene expression by AIRE. J Immunol (2013) 190:2479-82. doi: 10.4049/jimmunol.1203210

51. Pitkänen J, Doucas V, Sternsdorf T, Nakajima T, Aratani S, Jensen $\mathrm{K}$, et al. The autoimmune regulator protein has transcriptional transactivating properties and interacts with the common coactivator CREB-binding protein. J Biol Chem (2000) 275:16802-9. doi:10. 1074/jbc.M908944199

52. Ruan QG, Tung K, Eisenman D, Setiady Y, Eckenrode S, Yi B, et al. The autoimmune regulator directly controls the expression of genes critical for thymic epithelial function. I Immunol (2007) 178:717380.

53. Koh AS, Kuo AJ, Park SY, Cheung P, Abramson J, Bua D, et al. Aire employs a histone-binding module to mediate immunological tolerance, linking chromatin regulation 
with organ-specific autoimmunity. Proc Natl Acad Sci U S A (2008) 105:15878-83. doi:10.1073/ pnas. 0808470105

54. Org T, Chignola F, Hetényi C, Gae$\operatorname{tani}$ M, Liiv I, Maran U. The autoimmune regulator PHD finger binds to non-methylated histone $\mathrm{H} 3 \mathrm{~K} 4$ to activate gene expression. EMBO Rep (2008) 9:370-6. doi:10.1038/embor. 2008.11

55. Abramson J, Giraud M, Benoist C, Mathis D. Aire's partners in the molecular control of immunological tolerance. Cell (2010) 140: 123-35. doi:10.1016/j.cell.2009.12. 030

56. Liiv I, Rebane A, Org T, Saare M, Maslovskaja J, Kisand K, et al. DNAPK contributes to the phosphorylation of AIRE: importance in transcriptional activity. Biochim Biophys Acta (2008) 1783:74-83. doi: 10.1016/j.bbamcr.2007.09.003

57. Žumer K, Low AK, Jiang H, Saksela K, Peterlin BM. Unmodified histone H3K4 and DNA-dependent protein kinase recruit autoimmune regulator to target genes. $\mathrm{Mol} \mathrm{Cell}$ Biol (2012) 32:1354-62. doi:10. 1128/MCB.06359-11

58. Luo Z, Lin C, Shilatifard A. The super elongation complex (SEC) family in transcriptional control. Nat Rev Mol Cell Biol (2012) 13:543-7. doi:10.1038/nrm3417

59. Levine M. Paused RNA polymerase II as a developmental checkpoint. Cell (2011) 145:502-11. doi:10. 1016/j.cell.2011.04.021

60. Oven I, Brdicková N, Kohoutek J, Vaupotic T, Narat M, Peterlin BM. AIRE recruits $\mathrm{P}-\mathrm{TEFb}$ for transcriptional elongation of target genes in medullary thymic epithelial cells. Mol Cell Biol (2007) 27:8815-23. doi:10.1128/MCB.01085-07

61. Giraud M, Yoshida H, Abramson J, Rahl PB, Young RA, Mathis $D$, et al. Aire unleashes stalled RNA polymerase to induce ectopic gene expression in thymic epithelial cells. Proc Natl Acad Sci U S A (2012) 109:535-40. doi:10.1073/ pnas.1119351109

62. Macedo C, Evangelista AF, Marques MM, Octacílio-Silva S, Donadi EA, Sakamoto-Hojo ET, et al. Autoimmune regulator (Aire) controls the expression of microRNAs in medullary thymic epithelial cells. Immunobiology (2013) 218:554-60. doi:10.1016/j.imbio.2012.06.013

63. Ucar O, Tykocinski LO, Dooley J, Liston A, Kyewski B. An evolutionarily conserved mutual interdependence between Aire and microRNAs in promiscuous gene expression.
Eur J Immunol (2013) 43:1769-78. doi:10.1002/eji.201343343

64. Papadopoulou AS, Dooley J, Linterman MA, Pierson W, Ucar O, Kyewski B, et al. The thymic epithelial microRNA network elevates the threshold for infection-associated thymic involution via miR-29a mediated suppression of the IFN$\alpha$ receptor. Nat Immunol (2012) 13:181-7. doi:10.1038/ni.2193

65. Zuklys S, Mayer CE, Zhanybekova S, Stefanski HE, Nusspaumer G, Gill J, et al. MicroRNAs control the maintenance of thymic epithelia and their competence for $\mathrm{T}$ lineage commitment and thymocyte selection. J Immunol (2012) 189: 3894-904. doi:10.4049/jimmunol. 1200783

66. Poliani PL, Facchetti F, Ravanini M, Gennery AR, Villa A, Roifman CM, et al. Early defects in human T-cell development severely affect distribution and maturation of thymic stromal cells: possible implications for the pathophysiology of Omenn syndrome. Blood (2009) 114:105-8. doi:10. 1182/blood-2009-03-211029

67. Marrella V, Poliani PL, Fontana E, Casati A, Maina V, Cassani B, et al. Anti-CD3 $\epsilon$ mAb improves thymic architecture and prevents autoimmune manifestations in a mouse model of Omenn syndrome: therapeutic implications. Blood (2012) 120:1005-14. doi:10. 1182/blood-2012-01-406827

68. Aggarwal BB, Gupta SC, Kim JH. Historical perspectives on tumor necrosis factor and its superfamily: 25 years later, a golden journey. Blood (2012) 119:651-65. doi: 10.1182/blood-2011-04-325225

69. Hoffmann A, Baltimore D. Circuitry of nuclear factor kappaB signaling. Immunol Rev (2006) 210:17186. doi:10.1111/j.0105-2896.2006. 00375. $\mathrm{x}$

70. Oeckinghaus A, Hayden MS, Ghosh S. Crosstalk in NF- $\mathrm{kB}$ signaling pathways. Nat Immunol (2011) 12:695-708. doi:10.1038/ni.2065

71. Vallabhapurapu S, Karin M. Regulation and function of NF-kappaB transcription factors in the immune system. Annu Rev Immunol (2009) 27:693-733. doi:10.1146/annurev. immunol.021908.132641

72. Sun SC. The noncanonical NF- $\mathrm{KB}$ pathway. Immunol Rev (2012) 246:125-40. doi:10.1111/j.1600065X.2011.01088.x

73. Burkly L, Hession C, Ogata L, Reilly C, Marconi L, Olson D, et al. Expression of relB is required for the development of thymic medulla and dendritic cells. Nature (1995) 373:531-6. doi:10.1038/373531a0

74. Weih F, Carrasco D, Durham S, Barton D, Rizzo C, Ryseck $\mathrm{R}$, et al. Multiorgan inflammation and hematopoietic abnormalities in mice with a targeted disruption of RelB, a member of the NF-kappa B/Rel family. Cell (1995) 80:331-40. doi:10.1016/ 0092-8674(95)90416-6

75. Heino M, Peterson P, Sillanpää N, Guérin S, Wu L, Anderson G, et al. RNA and protein expression of the murine autoimmune regulator gene (Aire) in normal, RelB-deficient and in NOD mouse. Eur J Immunol (2000) 30:1884-93. doi:10.1002/ 1521-4141(200007)30:7<1884: :AID-IMMU1884>3.0.CO;2-P

76. Kajiura F, Sun S, Nomura T, Izumi $\mathrm{K}$, Ueno $\mathrm{T}$, Bando $\mathrm{Y}$, et al. NFkappa B-inducing kinase establishes self-tolerance in a thymic stromadependent manner. J Immunol (2004) 172:2067-75.

77. Miyawaki S, Nakamura Y, Suzuka $\mathrm{H}$, Koba M, Yasumizu R, Ikehara $S$, et al. A new mutation, aly, that induces a generalized lack of lymph nodes accompanied by immunodeficiency in mice. Eur J Immunol (1994) 24:429-34. doi:10.1002/eji. 1830240224

78. Shinzawa M, Maruyama Y, Qin J, Akiyama N, Miyauchi M, Yanai $\mathrm{H}$, et al. Splenic extramedullary hemopoiesis caused by a dysfunctional mutation in the NF- $\mathrm{KB}$-inducing kinase gene. Biochem Biophys Res Commun (2011) 414:773-8. doi:10. 1016/j.bbrc.2011.10.001

79. Kinoshita D, Hirota F, Kaisho T, Kasai M, Izumi K, Bando Y, et al. Essential role of IkappaB kinase alpha in thymic organogenesis required for the establishment of self-tolerance. J Immunol (2006) 176:3995-4002.

80. Lomada D, Liu B, Coghlan L, Hu Y, Richie ER. Thymus medulla formation and central tolerance are restored in IKKalpha-/- mice that express an IKKalpha transgene in keratin $5+$ thymic epithelial cells. J Immunol (2007) 178 829-37.

81. Zhang B, Wang Z, Ding J, Peterson P, Gunning WT, Ding HF. NFkappaB2 is required for the control of autoimmunity by regulating the development of medullary thymic epithelial cells. J Biol Chem (2006) 281:38617-24. doi:10.1074/ jbc.M606705200

82. Zhu M, Chin RK, Christiansen PA, Lo JC, Liu X, Ware C, et al. NF-kappaB2 is required for the establishment of central tolerance through an Aire-dependent pathway. J Clin Invest (2006) 116:296471. doi:10.1172/JCI28326

83. Franzoso G, Carlson L, Xing L, Poljak L, Shores EW, Brown KD, et al. Requirement for NF-kappaB in osteoclast and B-cell development. Genes Dev (1997) 11:3482-96. doi: 10.1101/gad.11.24.3482

84. Inoue J, Gohda J, Akiyama T. Characteristics and biological functions of TRAF6. Adv Exp Med Biol (2007) 597:72-9. doi:10.1007/978-0-38770630-6_6

85. Qin J, Konno H, Ohshima D, Yanai H, Motegi H, Shimo Y, et al. Developmental stage-dependent collaboration between the TNF receptorassociated factor 6 and lymphotoxin pathways for B cell follicle organization in secondary lymphoid organs. I Immunol (2007) 179:6799-807.

86. Akiyama T, Maeda S, Yamane S, Ogino K, Kasai M, Kajiura $\mathrm{F}$, et al. Dependence of selftolerance on TRAF6-directed development of thymic stroma. Science (2005) 308:248-51. doi:10. 1126/science.1105677

87. Chiffoleau E, Kobayashi T, Walsh M, King C, Walsh P, Hancock W, et al. TNF receptor-associated factor 6 deficiency during hemopoiesis induces Th2-polarized inflammatory disease. J Immunol (2003) 171:5751-9.

88. Namjou B, Choi CB I, Harley T, Alarcón-Riquelme ME, Kelly JA, Glenn SB, et al. Evaluation of TRAF6 in a large multiancestral lupus cohort. Arthritis Rheum (2012) 64:1960-9. doi:10.1002/art. 34361

89. Raychaudhuri S, Thomson BP, Remmers EF, Eyre S, Hinks A, Guiducci C, et al. Genetic variants at CD28, PRDM1 and CD2/CD58 are associated with rheumatoid arthritis risk. Nat Genet (2009) 41:13138. doi:10.1038/ng.479

90. Akiyama T, Shimo Y, Yanai $H$, Qin J, Ohshima D, Maruyama Y, et al. The tumor necrosis factor family receptors RANK and CD40 cooperatively establish the thymic medullary microenvironment and self-tolerance. Immunity (2008) 29:423-37. doi:10.1016/ j.immuni.2008.06.015

91. Danzl NM, Donlin LT, Alexandropoulos K. Regulation of medullary thymic epithelial cell differentiation and function by the signaling protein Sin. $J$ Exp Med (2010) 207:999-1013. doi:10.1084/jem.20092384 
92. Alexandropoulos K, Danzl NM. Thymic epithelial cells: antigen presenting cells that regulate $\mathrm{T}$ cell repertoire and tolerance development. Immunol Res (2012) 54:177-90. doi:10.1007/s12026-012-8301-y

93. Alexandropoulos K, Baltimore D. Coordinate activation of c-Src by SH3- and SH2-binding sites on a novel p130Cas-related protein, Sin. Genes Dev (1996) 10:1341-55. doi: 10.1101/gad.10.11.1341

94. Ishino M, Ohba T, Sasaki H, Sasaki T. Molecular cloning of a cDNA encoding a phosphoprotein, Efs, which contains a Src homology 3 domain and associates with Fyn. Oncogene (1995) 11:2331-8.

95. Chin RK, Lo JC, Kim O, Blink SE, Christiansen PA, Peterson $\mathrm{P}$, et al. Lymphotoxin pathway directs thymic Aire expression. Nat Immunol (2003) 4:1121-7. doi:10.1038/ni982

Conflict of Interest Statement: The authors declare that the research was conducted in the absence of any commercial or financial relationships that could be construed as a potential conflict of interest.

Received: 07 June 2013; paper pending published: 24 June 2013; accepted: 09 August 2013; published online: 26 August 2013.

Citation: Akiyama T, Shinzawa $M$, Qin J and Akiyama N (2013) Regulations of gene expression in medullary thymic epithelial cells required for preventing the onset of autoimmune diseases. Front. Immunol. 4:249. doi: 10.3389/fimmu.2013.00249
This article was submitted to T Cell Biology, a section of the journal Frontiers in Immunology.

Copyright (c) 2013 Akiyama, Shinzawa, Qin and Akiyama. This is an open-access article distributed under the terms of the Creative Commons Attribution License (CC BY). The use, distribution or reproduction in other forums is permitted, provided the original author(s) or licensor are credited and that the original publication in this journal is cited, in accordance with accepted academic practice. No use, distribution or reproduction is permitted which does not comply with these terms. 